\title{
Galectin-1 Is Overexpressed in Nasal Polyps under Budesonide and Inhibits Eosinophil Migration
}

\author{
Carine Delbrouck, Isabelle Doyen, Nathalie Belot, Christine Decaestecker, \\ Rose Ghanooni, Aurore de Lavareille, Herbert Kaltner, Georges Choufani, \\ André Danguy, Guy Vandenhoven, Hans-Joachim Gabius, Sergio Hassid, and \\ Robert Kiss
}

\begin{abstract}
E.N.T. (CD, RG, GC, SH) and Immunology Departments (A de L), Erasmus University Hospital, and Laboratory of Histopathology (ID, NB, CD, AD, RK), Faculty of Medicine, Université Libre de Bruxelles, and Medical Department (GV), N.V. AstraZeneca A.S., Brussels, Belgium; and Institute of Physiological Chemistry (HK, H-JG), Faculty of Veterinary Medicine, Ludwig-Maximilians-University, Munich, Germany
\end{abstract}

\begin{abstract}
SUMMARY: Because of the importance of galectins for various cellular activities, the influence of the glucocorticoid budesonide on the level of expression of galectins -1 and -3 was investigated in human nasal polyposis. Ten nasal polyps obtained from surgical resection were maintained for 24 hours in the presence of various concentrations of budesonide. As quantitatively demonstrated by means of computer-assisted microscopy, $250 \mathrm{ng} / \mathrm{ml}$ (the highest dose tested) induced a pronounced increase of galectin-1 expression. This feature was observed in nasal polyps from allergic patients but not in those from nonallergic patients. Since eosinophils represent the main inflammatory cell population in nasal polyps, we investigated the effect of galectin-1 on their migration levels by means of quantitative phase-contrast computer-assisted videomicroscopy. Our results show that galectin-1 (coated on plastic supports) markedly reduced the migration levels of eosinophils in comparison to P-selectin. On the cellular level, marked modifications in the polymerization/depolymerization dynamics of the actin cytoskeleton (as revealed by means of computer-assisted fluorescence microscopy) and, to a much lesser extent, an increase in the adhesiveness of eosinophils to tested substrata were detectable. The present study therefore reveals a new galectin-1-mediated mechanism of action for glucocorticoid-mediated anti-inflammatory effects. (Lab Invest 2002, 82:147-158).
\end{abstract}

$T$ he cause and pathogenesis of nasal polyposis have still not been clarified, and nasal polyps could in fact represent a de novo inflammatory growth on the lateral wall of the nose or arise from the anterior ethmoidal cells (Bernstein et al, 1995). The predominant inflammatory cells in nasal polyps are eosinophils, which may therefore play prominent roles in the immunologic and inflammatory processes in nasal polyps (Bernstein et al, 1995; Stoop et al, 1992, 1993). Glucocorticoids are already used in hospitals to treat nasal polyps (Bachert and Gevaert, 1999; Barnes, 1998; Stoop et al, 1992) because they suppress inflammation processes by acting at different target sites. It is widely known that glucocorticoids regulate gene expression of pro- and anti-inflammatory effectors extending to adhesion molecules such as E-selectin, intercellular adhesion molecules (ICAMs), and certain mucins (Cronstein et al, 1992; Holgate and Mavroleon, 1998; Rothenberg, 1998; Tingsgaard et al,

Received September 4, 2001.

This study was supported by research grants awarded by the Fonds de la Recherche Scientifique Médicale (FRSM, Belgium), AstraZeneca (Brussels, Belgium), and the W.-Sander-Shiftung (Munich, Germany).

Address reprint requests to: Dr. Robert Kiss, Laboratoire d'Histopathologie, Faculté de Médecine, Université Libre de Bruxelles, 808 route de Lennik, 1070 Brussels, Belgium.E-mail: rkiss@ulb.ac.be
1998). Since glycans of cellular glycoconjugates (glycoproteins, glycolipids) are increasingly considered to present code units to endogenous receptors (Gabius, 2000; Reuter and Gabius, 1999), it is reasonable to propose that the anti-inflammatory potency of glucocorticoids can involve an as yet undescribed modulation of eosinophil activity via this information pathway. This reasoning prompted us to study the expression and functionality of galectins in this system.

Based on binding and cross-linking distinct ligands such as glycans on laminin, IgE glycoforms and IgE receptor $\left(\mathrm{F}_{\mathrm{c}} \varepsilon \mathrm{RI}\right)$, integrins or $\mathrm{CD} 2, \mathrm{CD} 3, \mathrm{CD} 7$ and CD45 galectins are implicated in different mechanisms including cell adhesion, growth, and apoptosis regulation and allergic reactions (Gabius, 1997; Kaltner and Stierstovfer, 1998; Liu, 1993; Perillo et al, 1998). In fact, galectin-1 has been shown to downregulate cell matrix adhesion and production of inflammatory effectors, such as prostaglandin $\mathrm{E}_{2}$ or IFN- $\gamma$ from stimulated $T$ cells or macrophages, and to provide a perspective to combat activated T cell-dependent diseases via induction of T cell-apoptosis (André et al, 1999; Levi et al, 1983; Offner et al, 1990; Rabinovich et al, 1999a, 1999b, 2000; Santucci et al, 2000). Ten-fold overexpression of this gene concurrent with onset of glucocorticoid-induced apoptosis in the susceptible human $T$ cell leukemia line CEM C7 
implicates this lectin in glucocorticoid-mediated lymphocytolysis (Goldstone and Lavin, 1991). Regulation of galectin- 1 by mechanisms at the level of transcription, translation, or degradation has also been noted during postnatal rat lung development, in which stage and duration of treatment with dexamethasone were found to be critical (Clerch et al, 1987; Sandford et al, 1993). Transcriptional regulation can be attributed to the presence of a putative steroid-binding site located at -210 in the galectin-1 gene (Gitt and Barondes, 1991). This background information explains why we addressed the question of whether a glucocorticoid might modulate galectin-1 expression in human nasal polyps. For this purpose ex vivo organotypical cultures of human nasal polyps, treated with budesonide or left untreated, were used. Besides monitoring galectin-1 we also measured galectin-3, a growth factor-inducible family member without known steroid-responsive regulation (Kadrofske et al, 1998).

In addition to protein expression, the levels of accessible binding sites required for functional activity were assessed with the labeled galectins. Thus expression levels for the galectins and their binding sites were quantitatively determined by means of computer-assisted microscopy as described previously (Camby et al, 2001; Gordower et al, 1999). RT-PCR analysis and Western blotting served as positive controls. Our data showed that budesonide markedly increased the level of galectin-1 expression in human nasal polyps. Next, we investigated whether galectin-1 can modulate the levels of migration, adhesion, and activation of human eosino- phils. The levels of eosinophil migration on galectin-1 and P-selectin (as bioactive control)coated culture supports were monitored in vitro by means of quantitative phase-contrast computerassisted videomicroscopy (De Hauwer et al, 1997, 1998; Nagy et al, 2001); the levels of eosinophil adhesion were measured by counting the number of eosinophils adhering to P-selectin and galectin-1coated culture supports. The extent of eosinophil activation was assessed by means of quantitative computer-assisted fluorescence microscopy with the eosinophil cationic protein (ECP) in eosinophils cultured on P-selectin- and galectin-1-coated supports.

\section{Results}

\section{RT-PCR and Western Blotting Analyses}

RT-PCR analysis reported in Figure 1 (bottom) shows that two polyps (P1 and P2) presented significant amounts of the amplification products for both galectin-1 and -3 mRNAs. The two Western blot panels (top), performed on the two same polyps, confirm protein expression. They also document the immunospecificity of the two polyclonal antibodies by using recombinant galectin- 1 and -3 as positive controls $(\mathrm{C}+)$, respectively. Galectin-1 Western blot analysis shows that when present in large amounts, galectin-1 (subunit mol wt $14 \mathrm{kd}$ ) can oligomerize even under reducing conditions. The lack of crossreactivity between homologous galectin-1 and galectin-3, re-
Western blot gal 1

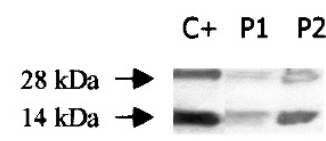

PCR $\beta$-actin

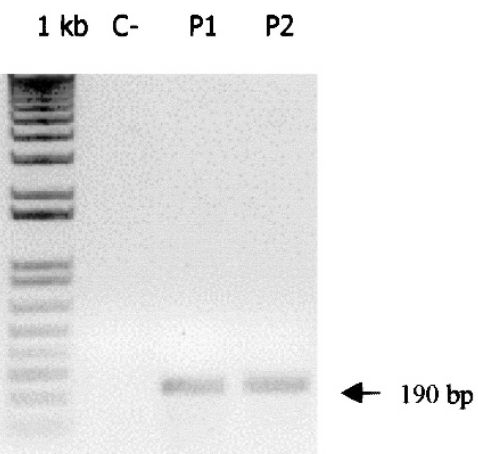

Western blot gal 3

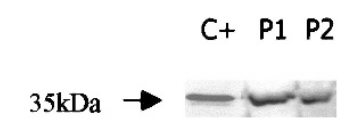

PCR gal $1 \quad$ PCR gal 3

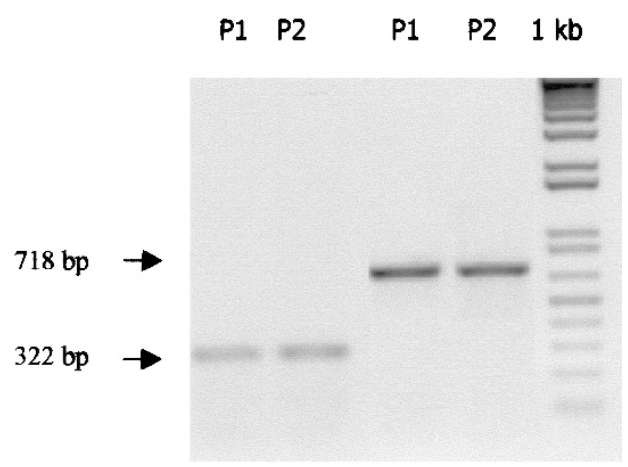

Figure 1.

Galectin-1 and -3 expression in polyps analyzed by means of Western blotting and RT-PCR on two different polyp samples (P1 and P2). In Western blotting we used recombinant galectin-1 and galectin-3 as positive controls $(C+)$. The molecular weight of galectin- 1 is $14 \mathrm{kd}$ and galectin- 3 is $35 \mathrm{kd}$. The $\beta$-actin-specific PCR analysis served as inherent control to show the integrity of the cDNA and the homogeneity of the sample used for the galectin-specific PCR analyses. The specific primer pairs used for the two galectins yield amplicon sizes of 322 bp for galectin-1 and 718 bp for galectin-3. 
ported previously for the polyclonals (Kopitz et al, 1998), was also ascertained (data not shown).

\section{Morphologic Illustration of the Immunohistochemical Expression of Galectin-1 in Organotypical Cultures of Human Nasal Polyps}

Although Figure 2A morphologically illustrates the pattern of immunohistochemical expression of galectin-1 in a piece of nasal polyp maintained for 24 hours under organotypical culture conditions in the absence of budesonide, Figure $2 \mathrm{~B}$ shows this pattern in the presence of $250 \mathrm{ng}$ of budesonide/ml MEM. These pieces came from two polyps from allergic patients showing an actual difference in galectin-1 expression. Evidently, the nasal polyp morphology and histologic structures were well preserved under the organotypical culture conditions used. Furthermore, whereas galectin-1 was weakly expressed in the different tissue layers in the absence of budesonide (Fig. 2A), budesonide markedly increased galectin-1 presence (cf. Fig. 2B). This increase was not so evident in polyps from nonallergic patients (not shown) as quantitatively confirmed below.

\section{Budesonide-Mediated Effects on Expression of Galectin-1 and -3 and Their Binding Sites}

All the budesonide-related data in Figure 3 were obtained at the $250 \mathrm{ng} / \mathrm{ml}$ concentration (labeled

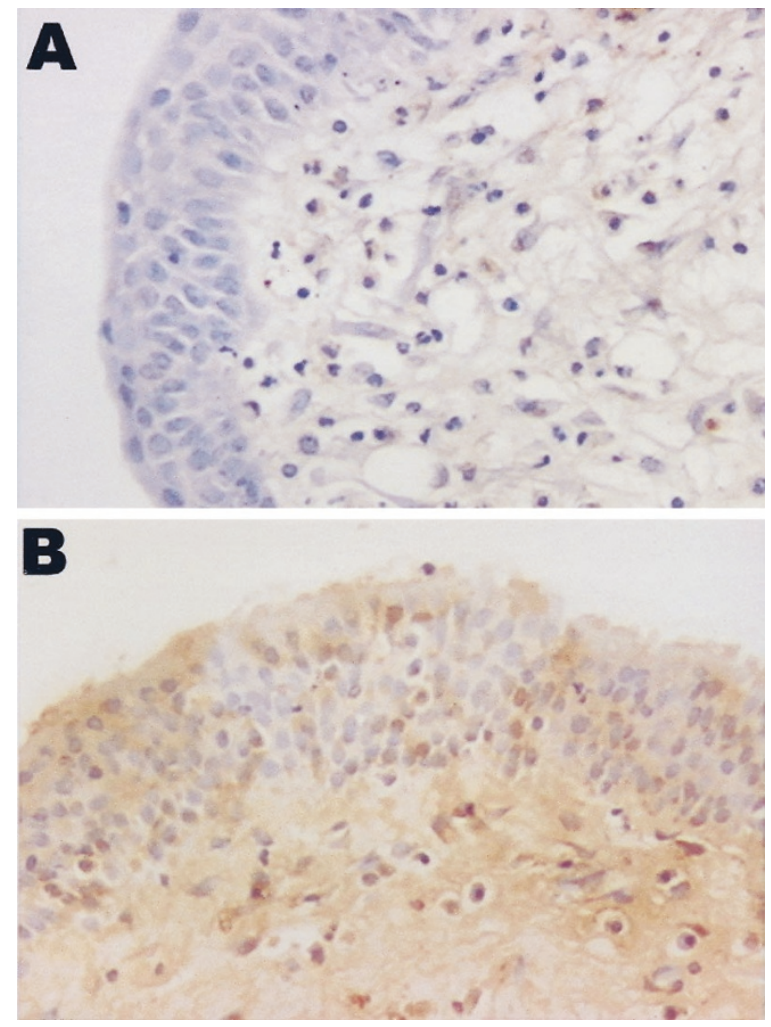

Figure 2.

Morphologic illustrations $(\times 200)$ of the immunohistochemical expression of galectin-1 in two nasal polyp pieces maintained for 24 hours under organotypical culture conditions in the absence of budesonide $(A)$ and the presence of $250 \mathrm{ng}$ of budesonide/ml MEM (B).
R250). For clarity, the data obtained with the two other concentrations (ie, 10 and $50 \mathrm{ng} / \mathrm{ml}$ ) are not reported because they were associated with weaker levels of statistical significance than the data for the $250 \mathrm{ng} / \mathrm{ml}$ concentration. The $p$ values reported in Figure 3 concern the statistical significance levels $(<0.05)$ associated with the differences observed between the treated (R250) and the untreated condition (CT). Figure 3 shows that a constant and very significant budesonide-mediated increase in galectin-1 expression was observed in the surface epithelium $(+38 \%$ on average), the glandular epithelium ( $+51 \%$ on average), and the connective tissues ( $+65 \%$ on average) of the nasal polyps from the allergic (ALL) patients. A marginal budesonide-mediated effect was observed in the nonallergic (N-ALL) patients. Concerning binding sites budesonide treatment did not significantly $(p>0.05)$ modify their expression in the nasal polyps regardless of whether they were obtained from the allergic or the nonallergic patients. A very significant budesonidemediated increase in galectin-3 expression was observed in the connective tissues of the nonallergic patients. The same feature was observed with respect to the level of galectin-3 binding site expression in the connective tissues of the allergic patients. A slight effect was observed in the surface epithelium of the nonallergic patients with respect to the galectin-3 level of expression.

As detailed below, the marked and constant budesonide-mediated increase in galectin-1 expression in all the histologic structures of the nasal polyps from the allergic patients prompted us to investigate whether galectin-1 was able to significantly modify the biologic behavior of eosinophils.

\section{Galectin-1-Mediated Effects on Eosinophil Migration}

Figure 4A illustrates (at a $\times 200$ magnification) the morphologic aspects of human eosinophils plated on a P-selectin substratum: they appear as refringent white dots. Figure 4B presents the migration pattern of these eosinophils over a 12-hour period of quantitative videomicroscopy on this P-selectin substratum. Figure $5 \mathrm{~A}$ schematically illustrates the two quantitative variables that we used to characterize the level of eosinophil migration. The AS variable is the average speed (the full trajectory length divided by the time used to cover it), whereas the maximum relative distance from the origin (MRDO) variable measures the greatest linear distance covered by each eosinophil (since the beginning of the experiment) normalized by the duration of the cell observation. These two variables therefore enable very distinct migratory behavior patterns to be distinguished. While the cell in the upper left part of Figure 5A ("d1") covered a trajectory with a very short MRDO, even if the cell migration speed could be increased, the trajectory covered over the 12 hours of observation by the second cell ("d2") had a MRDO value about five times higher. As detailed below, Figure 5 ( $B$ to $D$ ) compares the MRDO and AS value distributions (in terms of median and quartiles) obtained on eosinophil trajectories with regard to the 
SURFACE EPITHELIUM

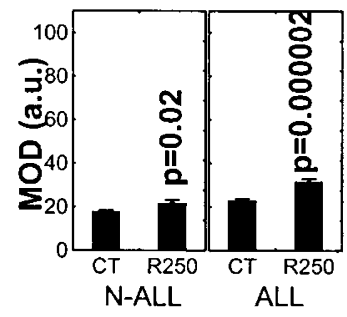

Gal-1

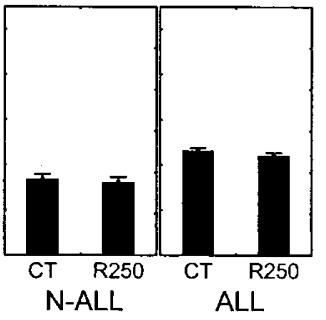

Gal-1 BS

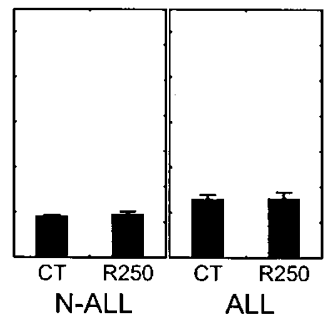

Gal-3

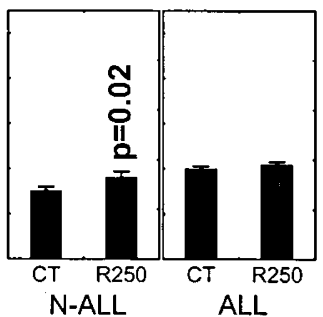

Gal-3 BS

\section{GLANDULAR EPITHELIUM}

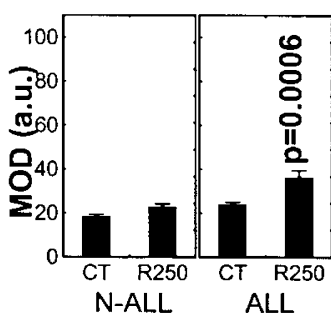

Gal-1

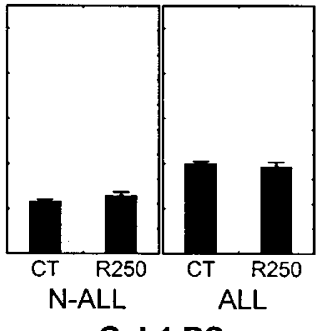

Gal-1 BS

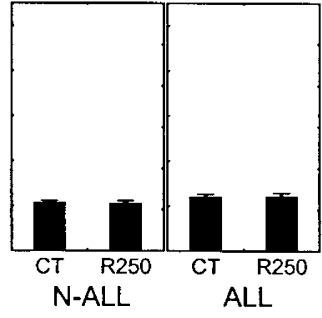

Gal-3

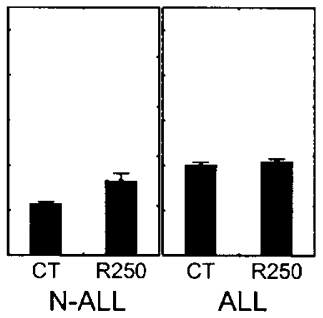

Gal-3 BS

\section{CONNECTIVE TISSUE}

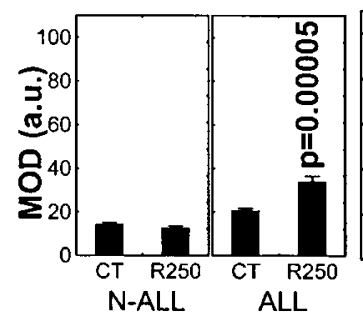

Gal-1

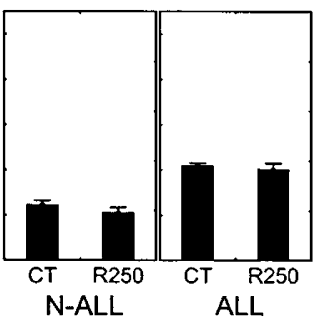

Gal-1 BS

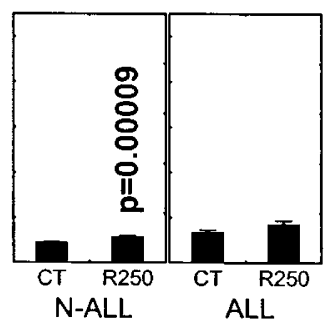

Gal-3

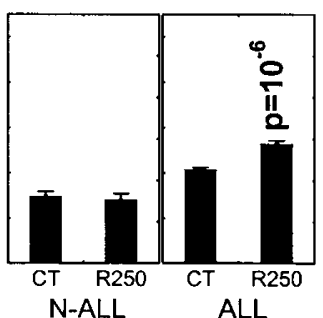

Gal-3 BS

Figure 3.

Quantitative evaluation (by means of computer-assisted microscopy) of the staining intensity (determined by means of the mean optical density variable) reflecting the expression of galectin-1 and -3 and their binding sites (BS) in nasal polyp samples treated with a concentration of $250 \mathrm{ng} / \mathrm{ml}$ (R250) of budesonide or left untreated (CT). This evaluation was performed on the surface and glandular epithelium and the connective tissue of the nasal polyp samples, and reported separately for the polyps from the nonallergic ( $\mathrm{N}-\mathrm{ALL}, n=5$ ) and the allergic patients (ALL, $n=5$ ). The data are reported as the mean and its standard error evaluated on 50 measurements (ie, 10 fields evaluated for each sample). MOD = mean optical density; a.u. = arbitrary units.

different supports and reports statistical comparisons (Mann-Whitney tests) with respect to the P-selectincoated support. Figure 5B shows that the largest relative distance covered by eosinophils (ie, the MRDO variable) on the plastic support was very similar $(p>0.05)$ to that on the P-selectin-coated support. In sharp contrast, the MRDO values characterizing eosinophils migrating on galectin-1-coated supports were markedly reduced when compared with the values obtained on P-selectin-coated supports (Fig. $5 \mathrm{~B})$. The average speed of eosinophil migration was very similar $(p>0.05)$ on plastic versus P-selectincoated supports over the first 6 hours of observation (Fig. 5C), whereas it significantly decreased on plastic alone between the 7 th and the 12 th hour of observa- tion (Fig. 5D). The migration speed of eosinophils on galectin-1-coated supports was noticeably greater over the first 6 hours of observation (Fig. 5C) and then it decreased markedly (Fig. 5D).

\section{Galectin-1-Mediated Effects on Eosinophil Adhesion and Actin Polymerization/Depolymerization Dynamics}

The marked galectin-1-induced decrease both in the greatest relative distance covered by the eosinophils and in their speeds of migration during 12 hours of observation (Fig. 5), prompted us to investigate whether this inhibitory effect on eosinophil migration corresponded to a similarly dramatic galectin-1-induced increase in eosinophil adhesion. Naturally, high 

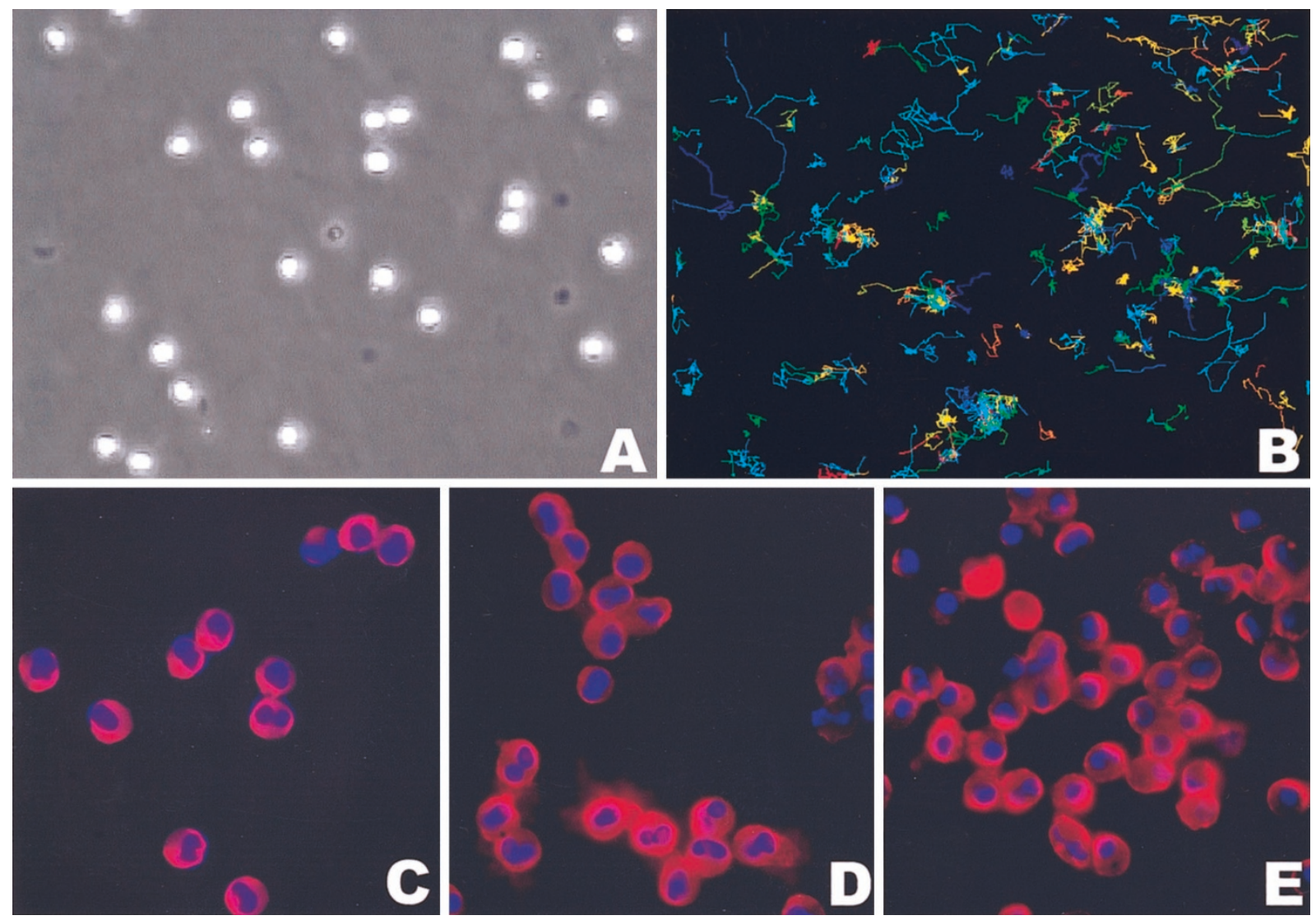

Figure 4.

A, shows the morphologic appearances $(\times 200)$ and B illustrates the trajectories of human eosinophils when migrating on a P-selectin-coated substratum. $C$ to $E$ document the immunofluorescence caused by the presence of eosinophil cationic protein (ECP) (red fluorescence) in eosinophils plated on plastic alone (C), and on P-selectin-coated (D) and galectin-1-coated (E) culture supports. DAPI staining (blue fluorescence) identifies the cell nuclei.

levels of adhesion will prevent high levels of migration (Palecek et al, 1997). Figure 6A shows that this was definitely not the case. In fact, only a slight increase in eosinophil adhesion level was observed when comparing cell behavior on the galectin-1-coated support and the plastic after 2 hours of observation (hatched bars). After 12 hours of observation (black bars), a significant increase in eosinophil adhesion level was seen for the lowest $\left(\mathrm{G}-0.1=0.1 \mu \mathrm{g} / \mathrm{cm}^{2}\right)$ and the intermediate $\left(\mathrm{G}-1=1 \mu \mathrm{g} / \mathrm{cm}^{2}\right)$ galectin-1 concentrations but not for the highest concentration (G-10 $=10$ $\mu \mathrm{g} / \mathrm{cm}^{2}$ ), when these galectin-coated supports were compared with the plastic or the P-selectin-coated ones. Thus, the marked galectin-1-induced decrease in eosinophil migration cannot be explained through a galectin-1-induced increase in their levels of adhesion to their substrata. We therefore investigated whether galectin-1 is able to modulate the organization of the actin cytoskeleton in eosinophils. Indeed, modifications to the actin polymerization/depolymerization dynamics result in marked modifications of cell migration (Lauffenburger and Horwitz, 1996). Figure 7A illustrates the morphologic aspect of the filamentous actin cytoskeleton pattern in human eosinophils plated on a P-selectin-coated support, whereas Figure 7B illustrates this pattern with respect to the glomerular actin cytoskeleton. The influence of P-selectin and galectin-1 with respect to glomerular versus filamentous actin amounts in human eosinophils is shown in Figure 7C. These data show that after 2 hours (hatched bars) of eosinophil plating on plastic alone, the glomerular (red fluorescence) to filamentous (green fluorescence) actin ratio was largely shifted to the filamentous actin (ratio $\mathrm{G} / \mathrm{F}<0.5$ ). With respect to plastic supports, plating these eosinophils for 2 hours on either P-selectin-coated or galectin-1-coated surfaces markedly decreased the polymerization of $\mathrm{G}$-actin (ratio $\mathrm{G} / \mathrm{F}>1.5$ ), with the maximum effects seen for the two highest galectin-1 concentrations tested (Fig. 7C). After 12 hours of plating, the ratio between glomerular and filamentous actin reached an equilibrium for the lowest galectin-1 concentration (ratio $\cong 1$ ), whereas glomerular actin was predominantly detected for the two highest galectin-1 concentrations tested here. Glomerular actin prevailed in eosinophils plated for 12 hours on P-selectin (Fig. 7C). Thus, the relatively similar $(p>0.05)$ migration rate for eosinophils plated on plastic alone as opposed to P-selectin-coated surfaces (Fig. 5) was associated with two completely opposite forms of actin cytoskeleton organization, namely a highly organized filamentous actin cytoskeleton for eosinophils plated on plastic alone (ratio $G / F<0.5$ ) and a weakly organized 

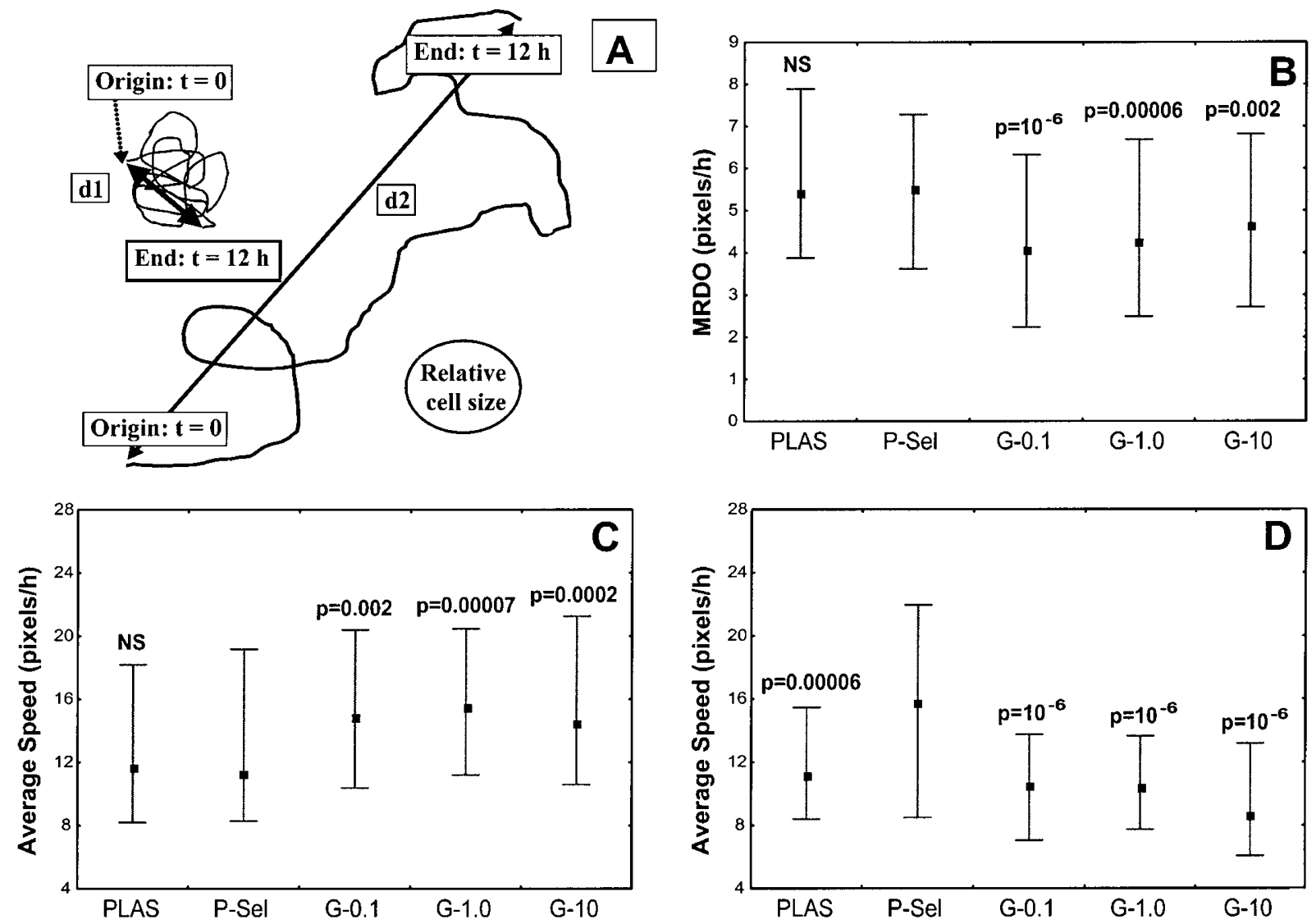

Figure 5 .

A, schematically illustrates the trajectories of two cells with different types of behavior pattern. Although the first moved randomly and remained in a small area, the second established a more extended trajectory (about five times the cell size). Each cell trajectory was characterized by two parameters. The first was the average speed (the AS variable) defined by the length of the cell trajectory divided by the time taken by the cell to cover it, whereas the second was the maximum relative distance from the origin (the MRDO variable). This parameter is defined by the greatest linear distance between the reference point ( $t=0)$ and any subsequent position of the cell (distances $\mathrm{d} 1$ and $\mathrm{d} 2$ in the figure) divided by the duration of the time of observation of the cell. $\mathrm{B}$, documents the variation (black squares = median, lower/upper bars = lower/upper quartiles; ie, 25/75\%) in the MRD0 values observed during the entire experimental period (12 hours) for eosinophils plated on different supports (PLAS = plastic, P-Sel $=0.2 \mu \mathrm{g} / \mathrm{cm}^{2}$ P-selectin, $\mathrm{G}-\mathrm{xx}=\mathrm{xx} \mu \mathrm{g} / \mathrm{cm}^{2}$ galectin-1 with densities of $0.1,1$, and $10 \mu \mathrm{g} / \mathrm{cm}^{2}$ ). The levels of significance ( $p$ values) were computed in relation to the P-selectin-coated support. Similarly, $C$ and $D$ report the variation in AS values observed during the first and last 6 hours of the experiment, respectively.

filamentous actin for eosinophils plated on the Pselectin-exposing surface (ratio $\mathrm{G} / \mathrm{F}>1.5$ ).

\section{Galectin-1-Mediated Effects on Eosinophil Activation}

Figure 4 ( $C$ to $E$ ) morphologically illustrate the levels of activation of eosinophils plated on plastic alone and on P-selectin-coated and galectin-1-coated surfaces as monitored by immunofluorescence targeted against ECP. The ECP staining intensity was determined quantitatively by means of computer-assisted fluorescence microscopy, as detailed in Figure 6B. Plating eosinophils on the surface with P-selectin as compared with plastic alone activated them significantly after 2 hours of plating (hatched bars), whereas no activation was seen after 12 hours of plating (black bars). Galectin-1 at all three of the concentrations tested activated the eosinophils markedly stronger than P-selectin. This effect remained observable after 12 hours of plating at the lowest dose tested for galectin-1 $\left(0.1 \mu \mathrm{g} / \mathrm{cm}^{2}\right)$. At higher doses (1 and 10 $\mu \mathrm{g} / \mathrm{cm}^{2}$ ) this effect was no longer reliably observable at this time point.

\section{Discussion}

As detailed in the "Introduction," nasal polyposis is a relevant model for the study of eosinophil-mediated inflammatory processes. As stated by Bernstein et al (1995), various hypotheses have been proposed to explain the cause of nasal polyps, with the two most plausible and widely discussed theories being allergy and inflammation. Eosinophil infiltration is a striking feature of nasal polyps: eosinophils are markedly more numerous in most nasal polyps than in the mucosa of the middle and inferior turbinates (Bernstein et al, 1995; Stoop et al, 1992, 1993). Increased numbers of macrophages and other lymphocytes are also observed in nasal polyps as compared with normal nasal mucosa (Bernstein et al, 1995; Stoop et al, 1992, 1993). These types of inflammatory cells, particularly eosinophils because of their large majority, increase 

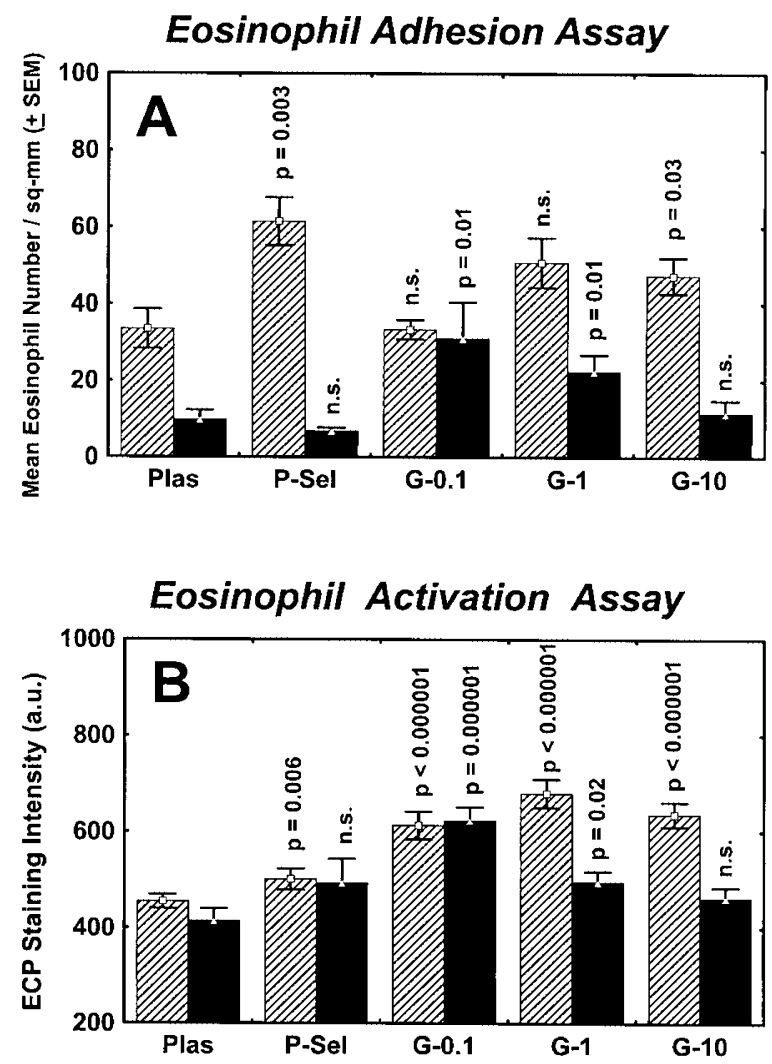

Figure 6.

A, shows the numbers (means \pm standard errors) of adherent eosinophils after 2 (hatched columns) and 12 (black columns) hours when plated at a concentration of $75,000 \mathrm{cell} / \mathrm{s} / \mathrm{ml}$ RPMI on five distinct substrata (legend similar to the one for Fig. 5). Similarly, B reports the levels of ECP-dependent immunofluorescence intensity for each coating condition. The levels of significance ( $p$-values) were computed in relation to data obtained with untreated plastic support.

the potential for immunologic reactivity in polyps as compared with turbinates (Bernstein et al, 1995). Cytokines and growth factors released from the resident cells of the nasal epithelium might also recruit inflammatory cells into nasal polyps, although the exact order of inflammatory cell interactions in the development of nasal polyposis is not yet precisely understood (Bernstein et al, 1995). The large majority of studies published on the anti-inflammatory effects of glucocorticoids focus on their action on the levels of expression of cytokines, chemokines, and growth factors (Bachert and Gevaert, 1999; Barnes, 1998). In aggregate, glucocorticoids mediate their antiinflammatory effects by increasing the transcription of anti-inflammatory genes (including, for example, lipocortin-1 and the leukocyte inhibitory protein) and by decreasing the transcription of inflammatory ones (including, for example, granulocyte macrophageCSF, exotoxin, IL-2, IL-3, IL-4, IL-11, IL-13, TNF- $\alpha$, RANTES and, in the first place, IL-5, all of which play major roles in eosinophil pathobiology) (Barnes, 1998; Holgate and Mavroleon, 1998; Rothenberg, 1998). Orchestrated by the hormones and mediators, adhesion molecules are actors in the migration of inflammatory cells towards an inflammatory site. Compared
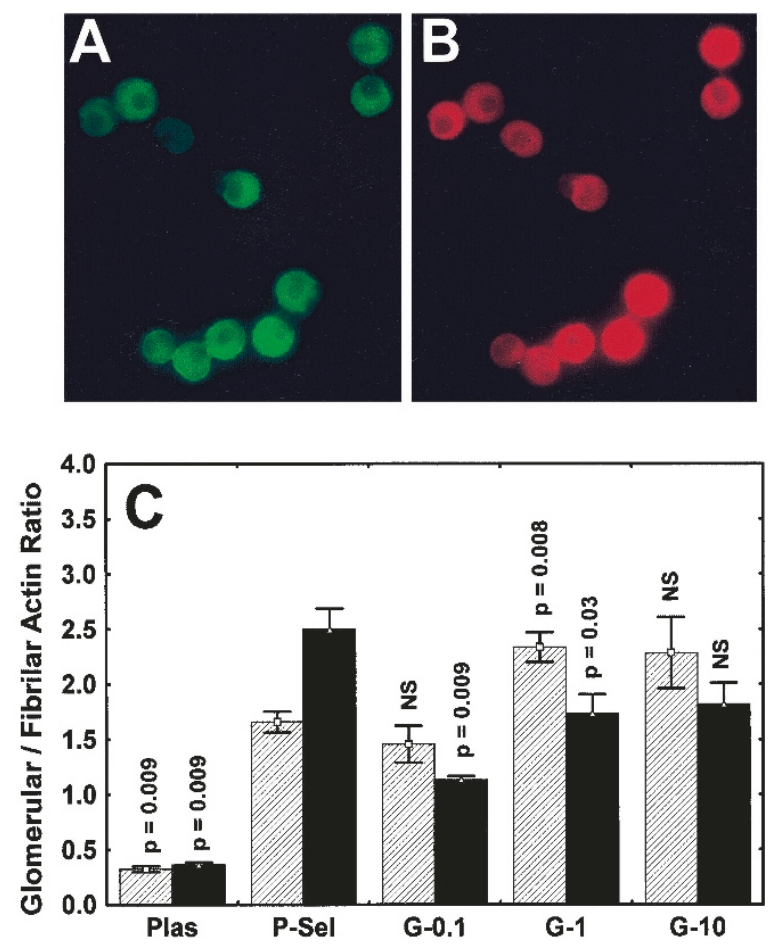

Figure 7.

$A$ and $B$, illustrate immunofluorescence of the fibrillary actin cytoskeleton (green) and the glomerular actin cytoskeleton (red) in human eosinophils plated on a P-selectin-coated support. C, shows (similarly to Fig. 6) the influence of the type of support on the relative amounts of glomerular versus filamentous actin in the human eosinophils reported here based on the ratio of the two immunofluorescence intensities (red/green). The levels of significance ( $p$ values) were computed in relation to data obtained with the P-selectin support.

with the cytokines and chemokines, less is known about glucocorticoid-mediated anti-inflammatory effects with respect to adhesion molecule expression. Most of these studies relate to ICAMs or vascular cellular adhesion molecules. For example, Tingsgaard et al (1998) used $100 \mu \mathrm{g}$ of budesonide administered twice daily in each nostril of 11 patients suffering from nasal polyposis and observed a budesonide-mediated down-regulation of ICAM-1 expression in the vascular endothelium in the nasal polyps. These authors argue that this effect might interfere with leukocyte extravasation and partially account for the anti-inflammatory effect of local glucocorticoid treatment in human nasal polyposis. In the present study, we used organotypical cultures of human nasal polyps and, as a validation of this methodology, we also observed a statistically significant budesonide-mediated decrease in the immunohistochemical expression of ICAM-1 in the cultured polyp pieces (not shown). In contrast, budesonide did not significantly modify the level of expression of $\mathrm{P}$-selectin in these organotypical nasal polyp cultures (not shown). P-selectin acts as a potent adhesion receptor (located on platelets and endothelial cells) for distinct glycoproteins on the eosinophil surface (Varki, 1997; Vestweber and Blanks, 1999). As outlined in the "Introduction," galectin-1 could be considered as a further target of glucocorticoids. Our data clearly indicate that the budesonide markedly 
increased the level of expression of galectin-1 in the different histologic nasal polyp structures analyzed from the five allergic patients. The fact that this was not observed in the nasal polyps from the five nonallergic patients has to be investigated. Presentation of accessible binding sites is not affected, and galectin-3, too, is apparently not subject to glucocorticoid regulation. The pronounced budesonidemediated increase in galectin-1 expression seems to translate into a notable decrease in eosinophil migration, a feature that was not observed with P-selectin. Thus, galectin- 1 acted as a nonpermissive substrate with respect to processes relevant for eosinophil migration. Biophysical measurements with atomic force microscopy make it unlikely that a firm and nearly irreversible adhesion is the reason for this effect (Dettmann et al, 2000), pointing to intracellular reactions instead. Interestingly, galectin-1 triggers the same reaction on tumor astrocytes (Camby et al, manuscript submitted for publication). Based on the biophysical data, we turned our attention to monitoring the organization of the actin cytoskeleton as a potential target site of galectin-1-initiated signaling. Indeed, obvious effects were detected in this respect with F- and G-actin-specific probes. Preliminary data that we recently obtained (not shown) suggest that the galectin-1-induced alterations of the organization of the actin cytoskeleton in eosinophils might be mediated through the activation of certain Rho GTPases. They represent one of the major classes of molecules controlling the organization of the actin cytoskeleton (Aspenström, 1999). In addition to the impact of galectin-1 on eosinophil migration, we also describe for the first time an effect on activation. As revealed by an obvious increase in the level of ECP expression, the highest two galectin-1 concentrations markedly activated the eosinophils plated on the galectin-coated surface. This feature was observed after 2 hours of plating and disappeared after 12 hours (except for the lowest coating concentration). Indeed, after 12 hours of high galectin-1 concentrations, the eosinophil ECP levels were similar to those observed in eosinophils plated onto plastic, ie, in nonactivated eosinophils. These data suggest that eosinophil activation was apparently favored in the lower section of the tested concentration range of galectin- 1 relative to the degranulation process, which seems to be sensitive to the highest-dose regimens. By increasing the level of galectin-1 expression, budesonide decreased the migration level of the eosinophils and, as shown by the ECP expression level, caused (at high doses) an acceleration in their degranulation process. This acceleration may adversely affect the maintenance of a chronic inflammatory state, thereby adding to the anti-inflammatory effects of budesonide resulting from the slowing down eosinophil motility. In conclusion, the present data describe a new functionality of galectin-1 on eosinophils, in the course of glucocorticoid treatment, different from the proapoptotic activity on susceptible $\mathrm{T}$ cells.

\section{Materials and Methods}

\section{Clinical Data and Histopathologic Characteristics}

Medical records and samples of nasal polyps were obtained for 10 patients, with the polyposis diagnoses made according to the classification that we reported previously (Hassid et al, 1997). The 10 nasal polyps in the present study involved massive polyposis and came from 5 allergic and 5 nonallergic patients. The allergic versus nonallergic status of the patients was determined on the basis of the skin prick test and total and specific IgE expression (Dreborg, 1993).

\section{Ex Vivo Organotypical Cultures of Human Nasal Polyps}

The 10 nasal polyps were maintained under organotypical culture conditions in a manner identical to the methodology that we have described for human brain (Camby et al, 1996), prostate (Janssen et al, 1997), colon (Philippart et al, 2000), and other cancer tissues (Gabius et al, 2001). Briefly, after their surgical removal, the nasal polyp specimens were rinsed twice in MEM (Gibco-Life Technologies, Merelbeke, Belgium) and immediately cut in half. One half was used for histopathologic diagnosis, while the other half was immediately divided into pieces measuring approximately $2 \mathrm{~mm}^{3}$. To overcome the problem of biologic heterogeneity, each experimental condition included between 10 and 15 randomly selected tissue pieces for each nasal polyp. These pieces were cultured for 24 hours in $30 \mathrm{~mm}$ (diameter) $\times 10 \mathrm{~mm}$ (height) Petri dishes (Nunc-Life Technologies, Merelbeke, Belgium) containing $3 \mathrm{ml}$ of culture medium in the form of MEM supplemented with a mixture of $0.6 \mathrm{mg} / \mathrm{ml}$ glutamine, $200 \mathrm{IU} / \mathrm{ml}$ penicillin, $200 \mathrm{IU} / \mathrm{ml}$ streptomycin, and 0.1 $\mathrm{mg} / \mathrm{ml}$ gentamicin (all from Gibco). The effects of three concentrations $(10,50$, and $250 \mathrm{ng} / \mathrm{ml})$ of budesonide (Rhinocord®; AstraZeneca, Brussels, Belgium) were studied. For this purpose, budesonide was first dissolved in a minimal amount of dimethyl sulfoxide, with the final dimethyl sulfoxide concentration of less than $0.1 \%$. An equal volume of this solution was added to the control cultures. After 24 hours of culture, the samples were fixed in buffered formalin for 5 days. After paraffin embedding, $5-\mu \mathrm{m}$ sections were prepared for quantitative histochemistry as detailed below.

\section{Determination of Expression of Galectin-1 and -3 and Their Accessible Binding Sites in Human Nasal Polyps by Means of Histochemistry}

Specific polyclonal antibodies and the label-free or biotinylated galectins were prepared as described in detail previously (Camby et al, 2001; Gabius et al, 1991; Gordower et al, 1999). For each treatment condition, 10 to 15 tissue pieces were embedded in the same paraffin block from which $5-\mu \mathrm{m}$-thick sections were cut. These sections were processed with the anti-galectin- 1 and -3 antibodies or the biotinylated galectins. Incubation with the marker-containing solutions was performed at $25 \pm 1^{\circ} \mathrm{C}$ for 30 minutes 
at a concentration of $10 \mathrm{gm} / \mathrm{ml}$. The extent of the specifically bound probes was visualized by means of avidin-biotin-peroxidase complex kit reagents (Vector Laboratories, Burlingame, California), with diaminobenzidine/ $\mathrm{H}_{2} \mathrm{O}_{2}$ as chromogenic substrates. The control reactions included the omission of the incubation step with the probe (antibody or galectin) and also with each of the secondary reagents to exclude any staining by binding of kit reagents, such as the glycoproteins avidin or peroxidase. Counterstaining with hematoxylin concluded the processing (see Fig. 1).

To evaluate the staining profiles, two quantitative variables were determined by means of a SAMBA 2005 computer-assisted microscope system (Samba Technologies, Grenoble, France) with a $\times 40$ (aperture $0.50)$ magnification lens. The labeling index reports the percentage of tissue area specifically stained by a given histochemical marker. The mean optical density (MOD) denotes staining intensity computed on the immunopositive areas only. Both the way in which we used the computer-assisted system to quantify the histochemical staining and the standardization procedures dealing with the manner in which we used the computer-assisted microscopy have been detailed elsewhere (Camby et al, 2001; Goldschmidt et al, 1996; Hassid et al, 1997). A negative histologic control slide (routine processing without the incubation step involving the primary antibody or the biotinylated galectin) was analyzed for each specimen under study. The software used on the computer-assisted microscope automatically subtracted the labeling index and MOD values of the negative control sample from each corresponding positive one.

As detailed previously (Hassid et al, 1997), three types of histologic structure were analyzed for each experimental condition, ie, the surface epithelium, the glandular epithelium, and the connective tissue (Fig. 2). Ten fields of between 60,000 and $120,000 \mu \mathrm{m}^{2}$ each were scanned for each histologic structure.

\section{RT-PCR Technique for Galectin-1 and Galectin-3 mRNA Detection in Human Nasal Polyps}

Total RNA was extracted from two distinct nasal polyps by means of Tripure isolation reagent (Roche Diagnostics, Mannheim, Germany). Five micrograms of RNA were used as a template for cDNA synthesis. Reverse transcription was performed for 50 minutes at $42^{\circ} \mathrm{C}$ in RT buffer (50 mm Tris/ $\mathrm{HCl}, \mathrm{pH} 8.3,75 \mathrm{~mm} \mathrm{KCl}$, $3 \mathrm{~mm} \mathrm{MgCl} 2$ ), $10 \mathrm{~mm}$ dithiothreitol, dNTPs (0.5 mM each), random hexamer primers $(5 \mathrm{ng} / \mu \mathrm{l})$, and 200 Superscript reverse transcriptase (Gibco, Karlsruhe, Germany). The reaction was terminated by incubation for 10 minutes at $70^{\circ} \mathrm{C}$. cDNA integrity was confirmed by $\beta$-actin-specific PCR analysis. The following primers were used for RT-PCR analysis: galectin- 1 sense $=5^{\prime}$ AAC CTG GAG AGT GCC TTC GA $3^{\prime}$ and galectin-1 antisense $=5^{\prime}$ GTA GTT GAT GGC CTC CAG GT 3'; galectin-3 sense = 5' ATG GCA GAC AAT TाT TCG CTC C $3^{\prime}$ and galectin-3 antisense $=5^{\prime}$ ATG TCA CCA GAA ATT CCC AGT T 3'.
All the PCR analyses were performed in 50- $\mu$ l reaction media containing $2 \mu \mathrm{l}$ of $\mathrm{cDNA}, 0.5 \mathrm{U}$ of Taq polymerase (Qiagen, Hilden, Germany), $50 \mathrm{~mm} \mathrm{KCl,} 20$ $\mathrm{mm}$ Tris/ $\mathrm{HCl}(\mathrm{pH} 9.0), 3 \mathrm{~mm} \mathrm{MgCl}_{2}$, dNTPs (0.5 mM each), and $0.4 \mu \mathrm{M}$ of both sense and antisense primers. The amplification was performed as follows: $94^{\circ} \mathrm{C}$ for 4 minutes, followed by 40 cycles at $94^{\circ} \mathrm{C}$ for 1 minute, $60^{\circ} \mathrm{C}$ for 1 minute, and $72^{\circ} \mathrm{C}$ for 2 minutes. After a final extension period of 10 minutes at $72^{\circ} \mathrm{C}$, the amplified products were separated by gel electrophoresis in 2\% Tris-acetate-EDTA (TAE) gels and visualized by ethidium bromide staining under ultraviolet light.

\section{Western Blotting Analyses}

Nasal polyp extracts were prepared by sonication in PBS (20 mM) containing $1 \mathrm{~mm}$ PMSF and $10 \mu \mathrm{g}$ of aprotinin $/ \mathrm{ml}$. Nasal polyp lysates containing $10 \mu \mathrm{g} / \mathrm{ml}$ of extracted proteins (determined by the bicinchoninic acid protein assay; Pierce, Polylabo, Antwerp, Belgium) were loaded into each lane of a $12 \%$ polyacrylamide gel under denaturing and reductive conditions. After electrophoresis, the proteins were transferred onto a Polyscreen polyvinylidene difluoride membrane (NEN Life Science Products, Boston, Massachusetts) by tank blotting. Galectins were immunodetected by affinity-purified rabbit polyclonal anti-galectin-1 and -3 specific antibodies $(1 \mu \mathrm{g} / \mathrm{ml}$ PBS containing $5 \%$ of milk powder) in conjunction with the conjugate of goat anti-rabbit immunoglobulin $\mathrm{G}$ and horseradish peroxidase $(0.2 \mu \mathrm{g} / \mathrm{ml}$; NEN). Control experiments included the omission of the incubation step with the antigalectin-1 or -3 antibodies (negative control; not shown) and the electrophoresis of $0.1 \mu \mathrm{g} / \mathrm{ml}$ of recombinant galectin-1 or -3 as positive controls (Fig. 1).

\section{Eosinophil Purification}

Eosinophils were purified from blood of healthy volunteers as previously described (Woerly et al, 1999). Briefly, granulocyte pellet, containing mainly neutrophils, eosinophils, and erythrocytes, was isolated by density gradient centrifugation on Lymphoprep ( $\mathrm{Ny}$ comed, Oslo, Norway). Erythrocytes were eliminated by hypotonic saline lysis. Eosinophils were further purified by incubation with anti-CD16- and anti-CD3bound immunomagnetic beads (Miltenyi Biotec Gmbh, Bergisch Glabdach, Germany) to eliminate contaminating neutrophils and lymphocytes, respectively. Eosinophils were separated from magnetically labeled neutrophils and lymphocytes by passage of cells on a magnetic cell sorter column (Miltenyi Biotec Gmbh). The purity of eosinophils was always $>95 \%$. The eosinophils so purified were then placed in culture media (RPMI; Gibco).

\section{Description of the Video Cell-Tracking System Used to Characterize the Influence of P-Selectin and Galectin-1 on In Vitro Eosinophil Motility Features}

The eosinophil motility levels were characterized by means of a device that is described in detail elsewhere 
(De Hauwer et al, 1997, 1998; Nagy et al, 2001). Briefly, this instrument consists of an inverted-phase contrast microscope equipped with a black and white CCD camera, an incubator maintaining the temperature at $37^{\circ} \mathrm{C}$, and a computer containing a frame grabber and image-processing software that analyses digitized frames. The software that we had previously developed enabled each living cell in the culture under study to be monitored separately and automatically on the basis of specific morphologic characteristics that, in turn, enabled the cells to be identified against their background (the plastic Falcon dishes). Once the segmentation procedure was complete, each cell was transformed into its center of gravity. Because an image was digitized every minute by the computer, the video system was able to track the trajectory of each cell by analyzing the movement of its center of gravity. From these trajectories the average speed (the AS quantitative variable) and the maximum relative distance from the origin (the MRDO quantitative variable) were calculated for each cell analyzed. The AS variable represents the speed of migration, whereas the MRDO variable describes the greatest linear distance found between the original and subsequent positions of a cell, divided by the observation time (De Hauwer et al, 1997, 1998). All the experiments were performed over 12 hours with a cell concentration of 75,000 eosinophil/ml RPMI, with one image being recorded every minute.

Eosinophils were plated on different supports, ie, regular plastic (control 1) or plastic supports precoated with (a) $0.2 \mu \mathrm{g} \mathrm{P}$-selectin $/ \mathrm{cm}^{2}$ (control 2), (b) galectin-1 at $0.1 \mu \mathrm{g} / \mathrm{cm}^{2}$, (c) galectin-1 at $1 \mu \mathrm{g} / \mathrm{cm}^{2}$, and (d) galectin-1 at $10 \mu \mathrm{g} / \mathrm{cm}^{2}$. A $0.2 \mu \mathrm{g} / \mathrm{cm}^{2}$ coating density has already been used by Cheresh et al (1989) for fibronectin and by Stroeken et al (1998) for laminin. The 1 and $10 \mu \mathrm{g} / \mathrm{cm}^{2}$ galectin- 1 coating concentrations were used to mimic the budesonide-mediated increase in galectin-1 expression (see "Results").

Experiments at each condition were performed in triplicate. A minimum of 202 and a maximum of 315 eosinophil trajectories were analyzed in each experimental condition on the basis of the triplicate analyses. The triplicate analyses were performed independently three times for three distinct eosinophil donors.

\section{Eosinophil Adhesion Assay}

Eosinophils were plated at a concentration of 75,000 cells/ml RPMI on different substrata, ie, regular plastic or plastic supports precoated with (a) $0.2 \mu \mathrm{g}$ Pselectin $/ \mathrm{cm}^{2}$, (b) galectin-1 at $0.1 \mu \mathrm{g} / \mathrm{cm}^{2}$, (c) galectin- 1 at $1 \mu \mathrm{g} / \mathrm{cm}^{2}$, or (4) galectin-1 at $10 \mu \mathrm{g} / \mathrm{cm}^{2}$. The numbers of adherent eosinophils were recorded after 2 and 12 hours of culture. Ten fields of $1 \mathrm{~mm}^{2}$ were analyzed per experimental condition, all of which were performed in triplicate.

\section{Eosinophil Activation Assay}

The extent of eosinophil activation was monitored with the EG2 monoclonal anti-human ECP/EPX antibody
(Pharmacia and Upjohn, Uppsala, Sweden), which binds to human ECP and eosinophil protein X/eosinophil-derived neurotoxin. EG2 therefore stains activated eosinophils (Tai et al, 1984). The eosinophils were plated at a concentration of $75,000 \mathrm{cells} / \mathrm{ml}$ RPMI on five distinct substrates, ie, regular plastic or plastic supports precoated with (a) $0.2 \mu \mathrm{g} \mathrm{P}$-selectin/ $\mathrm{cm}^{2}$, and galectin-1 at (b) $0.1 \mu \mathrm{g} / \mathrm{cm}^{2}$, (c) galectin-1 at $1 \mu \mathrm{g} / \mathrm{cm}^{2}$, or (d) galectin-1 at $10 \mu \mathrm{g} / \mathrm{cm}^{2}$. The ECP intensity was recorded in 100 individual eosinophils per each experimental condition by means of quantitative computer-assisted fluorescence microscopy (using a goat anti-mouse secondary antibody conjugated with Alexa 594 red fluorochrome; Molecular Probes Inc., Eugene, Oregon) after either 2 or 12 hours of plating on the above-mentioned substrata.

\section{Quantitative Immunofluorescence Analysis of the In Vitro Determination of Actin Polymerization/Depolymerization Dynamics}

The conversion of filamentous $(F)$ into monomeric or glomerular $(G)$ actin is a key element in the dynamic changes involved in cell motility (Theriot and Mitchison, 1991). The influence on actin polymerization of culturing eosinophils on plastic alone, or on P-selectin or galectin-1 precoated plastic surfaces, was therefore investigated with fluorescent probes specific to either F- or G-actin. The fluorescent phallotoxin derivative phallacidin was chosen to label the F-actin, and fluorescent DNase I was chosen for the G-actin (Knowles and McCulloch, 1992). Both compounds bind to actin subunits in a stoichiometric ratio (Knowles and McCulloch, 1992). The experimental protocol is as follows: eosinophil concentrations of 75,000 cells/ml RPMl were plated for 2 hours on plastic, $0.2 \mu \mathrm{g} / \mathrm{cm}^{2}$ P-selectin, and $0.1 \mu \mathrm{g} / \mathrm{cm}^{2}, 1$ $\mu \mathrm{g} / \mathrm{cm}^{2}$, or $10 \mu \mathrm{g} / \mathrm{cm}^{2}$ galectin-1 precoated plastic supports. After this 2-hour period of plating, the cells

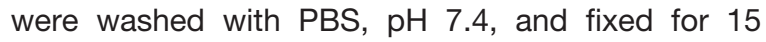
minutes with formaldehyde $4 \%$ in PBS. After three washes in PBS, the cells were permeabilized for 1 minute at $4^{\circ} \mathrm{C}$ with Tris-buffered saline $(10 \mathrm{~mm}$ Tris and $0.15 \mathrm{M} \mathrm{NaCl}, \mathrm{pH} 7.4$ ) containing $0.01 \%$ Triton $\mathrm{X}-100,2 \mathrm{~mm} \mathrm{MgCl}, 0.2 \mathrm{~mm}$ dithiothreitol, and 10\% glycerol $(\mathrm{v} / \mathrm{v})$. After three rinses in PBS, the cells were incubated for 2 hours at room temperature in a mixture of DNase I conjugated with Texas Red (DNasel-TR; Molecular Probes) at a final concentration of $10 \mu \mathrm{g} / \mathrm{ml}$ PBS and phallacidin conjugated with the fluoresceinlike fluorochrome BODIPY FL (Phall-FL; Molecular Probes) at a final concentration of $5 \mathrm{U} / \mathrm{ml}$ PBS. Methanol from the phallacidin stock solution was evaporated before dilution in PBS. After three to five rinses in PBS, the slides were mounted with Vectashield mounting medium (Vector Laboratories). The quantification of the intensities of green (F-actin) and red (G-actin) fluorescence was performed using a software developed by SAMBA Technologies. The computer-assisted microscope included a Zeiss Axioplan microscope (Zaventem, Belgium) equipped with excitation/emission filters of $590 / 615 \mathrm{~nm}$ for the 
DNasel-TR and of 505/512 for the Phall-FL, and with a Hamamatsu C4880 Dual-mode cooled CCD camera (Tokyo, Japan). For experiments at each experimental condition (performed in triplicate), photographs of 200 cells were taken (for both fluorochromes) with $a \times 100$ lens and at identical exposures for each (red or green) fluorescence.

\section{Statistical Analyses}

Statistical comparisons of the data were performed with the Student $t$ test (one-way variance analysis for two groups) after a check of the equality of variance using the Levene test and by the normal distribution fitting of the data by means of the $\chi^{2}$ test of goodness of fit. When these parametric conditions were not satisfied, the nonparametric Mann-Whitney test was performed. All the statistical analyses were performed using Statistica (Statsoft, Tulsa, Oklahoma).

\section{References}

André S, Kojima S, Yamazaki N, Kink C, Kaltner H, Kayser K, and Gabius H-J (1999). Galectins-1 and -3 and their ligands in tumor biology: Non-uniform properties in cell-surface presentation and modulation of adhesion to matrix glycoproteins for various tumor cell lines, in biodistribution of free and liposome-bound galectins and in their expression by breast and colorectal carcinomas with/without metastatic propensity. J Cancer Res Clin Oncol 125:461-474.

Aspenström P (1999). Effectors for the Rho GTPases. Curr Opin Cell Biol 11:95-102.

Bachert C and Gevaert P (1999). Effect of intranasal corticosteroids on release of cytokines and inflammatory mediators. Allergy 54(Suppl 57):116-123.

Barnes PJ (1998). Anti-inflammatory actions of glucocorticoids: Molecular mechanisms. Clin Sci 94:557572.

Bernstein JM, Gorfien J, and Noble B (1995). Role of allergy in nasal polyposis: A review. Otolaryngol Head Neck Surg 113:724-732.

Camby I, Belot N, Rorive S, Lefranc F, Maurage CA, Lahm H, Kaltner H, Hadari Y, Ruchoux MM, Brotchi J, Zick Y, Salmon I, Gabius HJ, and Kiss R (2001). Galectins are differentially expressed in supratentorial pilocytic astrocytomas, astrocytomas, anaplastic astrocytomas and glioblastomas, and significantly modulate tumor astrocyte migration. Brain Pathol 11:12-26.

Camby I, Salmon I, Danguy A, Pasteels J-L, Brotchi J, Martinez J, and Kiss R (1996). Influence of gastrin on human astrocytic tumor cell proliferation. J Natl Cancer Inst 88:594600.

Cheresh DA, Berliner SA, Vicente V, and Ruggeri ZM (1989). Recognition of distinct adhesive sites on fibrinogen by related integrins on platelets and endothelial cells. Cell 58:945953.

Clerch LB, Whitney PL, and Massaro D (1987). Rat lung lectin synthesis, degradation and activation: Developmental regulation and modulation by dexamethasone. Biochem $\mathrm{J} 245$ : 683-690.

Cronstein BN, Kimmel SC, Levin RI, Martiniuk F, and Weissmann G (1992). A mechanism for the antiinflammatory effects of corticosteroids: The glucocorticoid receptor regulates leukocyte adhesion to endothelial cells and expression of endothelial-leukocyte adhesion molecule 1 and intercellular adhesion molecule 1. Proc Natl Acad Sci USA 89:9991-9995.

De Hauwer C, Camby I, Darro F, Decaestecker C, Gras T, Salmon I, Kiss R, and Van Ham P (1997). Dynamic characterization of glioblastoma cell motility. Biochem Biophys Res Commun 232:267-272.

De Hauwer C, Camby I, Darro F, Migeotte I, Decaestecker C, Verbeek C, Danguy A, Pasteels J-L, Brotchi J, Salmon I, Van Ham P, and Kiss R (1998). Gastrin inhibits motility, decreases cell death and increases cell proliferation in human glioblastoma cell lines. J Neurobiol 37:373-382.

Dettmann W, Grandbois M, André S, Benoit M, Wehle AK, Kaltner H, Gabius H-J, and Gaub HE (2000). Differences in zero-force and force-driven kinetics of ligand dissociation for $\beta$-galactoside-specific proteins (plant and animal lectins, immunoglobulin G) monitored by plasmon resonance and dynamic single molecule force microscopy. Arch Biochem Biophys 383:157-170.

Dreborg S (1993). Allergy diagnosis. In: Mygind N, Naclerio $\mathrm{RM}$, editors. Allergic and non-allergic rhinitis: Clinical aspects. Copenhagen: Munksgaard.

Gabius H-J (1997). Animal lectins. Eur J Biochem 243:543576 .

Gabius H-J (2000). Biological information transfer beyond the genetic code: The sugar code. Naturwissenschaften 87:108121.

Gabius H-J, Darro F, Remmelink M, André S, Kopitz J, Danguy A, Gabius S, Salmon I, and Kiss R (2001). Evidence for stimulation of tumor proliferation in cell lines and histiotypic cultures by clinically relevant low doses of the galactoside-binding mistletoe lectin, a component of proprietary extracts. Cancer Invest 19:114-126.

Gabius H-J, Wosgien B, Hendrys M, and Bardosi A (1991). Lectin localization in human nerve by biochemically defined lectin-binding glycoproteins, neoglycoprotein and lectinspecific antibody. Histochemistry 95:269-277.

Gitt MA and Barondes SH (1991). Genomic sequence and organization of two members of a human lectin gene family. Biochemistry 30:82-89.

Goldschmidt D, Decaestecker C, Berthe JV, Gordower L, Remmelink M, Danguy A, Pasteels JL, Salmon I, and Kiss R (1996). The contribution of computer-assisted methods for histopathological classification of adipose tumors. Lab Invest 75:295-306.

Goldstone SD and Lavin MF (1991). Isolation of a cDNA clone, encoding a human $\beta$-galactoside-binding protein, overexpressed during glucocorticoid-induced cell death. Biochem Biophys Res Commun 178:746-750.

Gordower L, Decaestecker C, Kacem Y, Lemmers A, Gusman J, Burchert M, Danguy A, Gabius H-J, Salmon I, Kiss R, and Camby I (1999). Galectin-3 and galectin-3-binding site expression in human adult astrocytic tumors and related angiogenesis. Neuropathol Appl Neurobiol 25:319-330.

Hassid S, Decaestecker C, Hermans C, Salmon I, Pasteels J-L, Danguy A, and Kiss R (1997). Algorithm analysis of lectin glycohistochemistry and Feulgen cytometry for a new classification of nasal polyposis. Ann Otol Rhinol Laryngol 106: 1043-1051. 
Holgate ST and Mavroleon G (1998). The molecular and cell biology of allergy. J Laryngol Otol 112:1126-1137.

Janssen T, Pétein M, van Velthoven R, De Decker R, Assenmacher C, Corbusier A, Pasteels J-L, Kiss R, and Schulman R (1997). Coregulatory effects of epidermal growth factor, dihydrotestosterone and prolactin on benign human prostatic hyperplasia tissue culture proliferation. Prostate 30:47-52.

Kadrofske MM, Openo KP, and Wang JL (1998). The human LGALS3 (galectin-3) gene: Determination of the gene structure and functional characterization of the promoter. Arch Biochem Biophys 349:7-20.

Kaltner $\mathrm{H}$ and Stierstovfer B (1998). Animal lectins as cell adhesion molecules. Acta Anat 161:162-179.

Knowles GC and McCulloch CAG (1992). Simultaneous localization and quantification of relative $\mathrm{G}$ and $\mathrm{F}$ actin content: Optimization of fluorescence labeling methods. J Histochem Cytochem 40:1605-1612.

Kopitz J, von Reitzenstein C, Burchert M, Cantz M, and Gabius H-J (1998). Galectin-1 is a major receptor for ganglioside GM1, a product of the growth-controlling activity of a cell surface ganglioside sialidase, on human neuroblastoma cells in culture. J Biol Chem 273:11205-11211.

Lauffenburger DA and Horwitz AF (1996). Cell migration: A physically integrated molecular process. Cell 84:359-369.

Levi G, Tarrab-Hazdai R, and Teichberg VI (1983). Prevention and therapy with electrolectin of experimental autoimmune myasthenia gravis in rabbits. Eur $\mathrm{J}$ Immunol 13:500-507.

Liu F-T (1993). S-type mammalian lectins in allergic inflammation. Immunol Today 14:486-490.

Nagy N, Brenner C, Markadieu N, Chaboteaux C, Camby I, Schäfer BW, Pochet R, Heizmann CW, Salmon I, Kiss R, and Decaestecker C (2001). S100A2, a putative tumor suppressor gene, regulates in vitro squamous cell carcinoma migration. Lab Invest 81:599-612.

Offner H, Celnik B, Bringman TRS, Casentini-Borocz D, Nedurin GE, and Vandenbark AA (1990). Recombinant human $\beta$-galactoside-binding lectin suppresses clinical and histological signs of experimental autoimmune encephalomyelitis. J Neuroimmunol 28:177-184.

Palecek SP, Loftus JC, Ginsberg MH, Lauffenburger DA, and Horwitz AF (1997). Integrin-ligand binding properties govern cell migration speed through cell-substratum adhesiveness. Nature 385:537-540.

Perillo NL, Marcus ME, and Baum LG (1998). Galectins: Versatile modulators of cell adhesion, cell proliferation, and cell death. J Mol Med 76:402-412.

Philippart P, Harper L, Chaboteaux C, Decaestecker C, Bronckart Y, Gordower L, Lesueur-Ginot L, Malonne H, Lavergne O, Bigg D, da Costa PM, and Kiss R (2000). Homocamptothecin, an E-ring-modified camptothecin, exerts more potent antiproliferative activity than other topoisomerase I inhibitors in human colon cancers obtained from surgery and maintained in vitro under histotypical culture conditions. Clin Cancer Res 6:1557-1562.

Rabinovich GA, Ariel A, Hershkoviz R, Hirabayashi J, Kasai K-I, and Lieder O (1999a). Specific inhibition of T-cell adhesion to extracellular matrix and proinflammatory cytokine secretion by human recombinant galectin-1. Immunology 97:100-106.
Rabinovich GA, Daly G, Dreja H, Tailor H, Riera CM, Hirabayashi J, and Chernajovsky Y (1999b). Recombinant galectin-1 and its genetic delivery suppress collageninduced arthritis via T-cell apoptosis. J Exp Med 190:385397.

Rabinovich GA, Sotomayor CE, Riera CM, Bianco I, and Correa SG (2000). Evidence of a role for galectin-1 in inflammation. Eur J Immunol 30:1331-1339.

Reuter G and Gabius H-J (1999). Eukaryotic glycosylation: Whim of nature or multipurpose tool? Cell Mol Life Sci 55:368-422.

Rothenberg ME (1998). Eosinophilia. N Engl J Med 338: 1592-1600.

Sandford GL, Owens MA, and Odusanya BM (1993). Differential influence of dexamethasone on the activity and synthesis of $\beta$-galactoside-specific lectin (galaptin) during postnatal lung development. Exp Lung Res 19:91-104.

Santucci L, Fiorucci S, Cammilleri F, Servillo G, Federici B, and Morelli A (2000). Galectin-1 exerts immunomodulatory and protective effects on concanavalin A-induced hepatitis in mice. Hepathology 31:399-406.

Stoop AE, Van der Heijden HA, Biewenga J, and Vandarbaan $S$ (1992). Clinical aspects and distribution of immunologically active cells in the nasal mucosa of patients with nasal polyps after endoscopic sinus surgery and treatment with topical corticosteroids. Eur Arch Otorhinolaryngol 249:313-317.

Stoop AE, Van der Heijden HA, Biewenga J, and Vandarbaan $S$ (1993). Eosinophils in nasal polyps in nasal mucosa: An immunohistochemical study. J Allergy Clin Immunol 91:616622.

Stroeken PJ, van Rijthoven EA, van der Valk MA, and Roos E (1998). Targeted disruption of the $\beta 1$ integrin gene in a lymphoma cell line greatly reduces metastatic capacity. Cancer Res 58:1569-1577.

Tai PC, Spry CJ, Peterson C, Venge P, and Olsson I (1984). Monoclonal antibodies distinguish between storage and secreted forms of eosinophil cationic protein. Nature 309:182184.

Theriot JA and Mitchison TJ (1991). Actin microfilament dynamics in locomoting cells. Nature 352:126-131.

Tingsgaard PK, Larsen PL, Bock T, Lange-Vejlsgaard G, and Tos M (1998). Expression of intercellular adhesion molecule-1 on the endothelium in nasal polyps before, during and after topical glucocorticoid treatment. Acta Otolaryngol 118:404-408.

Varki A (1997). Selectin ligands: Will the real ones please stand up? J Clin Invest 99:158-162.

Vestweber D and Blanks JE (1999). Mechanisms that regulate the function of selectins and their ligands. Physiol Rev 79:181-213.

Woerly G, Roger N, Loiseau S, Dombrowicz D, Capron A, and Capron M (1999). Expression of CD28 and CD86 by human eosinophils and role in the secretion of type 1 cytokines (interleukin 2 and interferon gamma): Inhibition by immunoglobulin A complexes. J Exp Med 190:487-495. 